\title{
B-Type Natriuretic Peptide to Predict Ductus Intervention in Infants <28 Weeks
}

\author{
CHRISTOPH CZERNIK, JULIA LEMMER, BORIS METZE, PETRA S. KOEHNE, CHRISTIAN MUELLER, \\ AND MICHAEL OBLADEN
}

\author{
Department of Neonatology [C.C., B.M., P.S.K., M.O.], Institute of Laboratory Medicine [C.M.], Medical University Berlin, 13353 Berlin, \\ Germany; Department of Congenital Heart Disease [J.L.], Deutsches Herzzentrum Berlin, 13353 Berlin, Germany
}

\begin{abstract}
Patent ductus arteriosus (PDA) is frequent in neonates with gestational age of less than 28 wk. Clinical and echocardiographic signs define hemodynamic significance of PDA, but do not reveal the need for PDA intervention in the first days of life. B-type natriuretic peptide (BNP) has been proposed as a screening tool for PDA in preterm infants. To determine whether BNP can predict the need for PDA intervention, plasma BNP was measured by chemiluminescence immunoassay in 67 preterm infants $<28 \mathrm{wk}$ (median 26) on the second day of life in a prospective blinded study. PDA intervention was based on specified clinical and echocardiographic findings. Twenty-four patients (intervention group) received treatment for PDA and 43 patients (controls) remained without intervention. BNP concentrations were higher in the intervention (median $1069 \mathrm{pg} / \mathrm{mL}$ ) than in the control group ( $247 \mathrm{pg} / \mathrm{mL}, p<0.001)$. BNP correlated positively with ductal size $(R=0.46, p<0.001)$ and atrial/aortic root ratio $(R=0.54, p<0.001)$. In conclusion, plasma BNP proved to be a good predictor for ductus intervention (area under the curve: 0.86 ) with the best cutoff at $550 \mathrm{pg} / \mathrm{mL}$ on the second day of life in ventilated infants less than 28 wk gestation (sensitivity: $83 \%$; specificity: 86\%). (Pediatr Res 64: 286-290, 2008)
\end{abstract}

$\mathrm{P}$ reterm infants frequently have a patent ductus arteriosus (PDA), and its incidence is inversely related to gestational age $(1,2)$. Aortopulmonary shunting via the PDA leads to excessive blood overflow to the pulmonary system and prolonged ventilator dependency and contributes to bronchopulmonary dysplasia, feeding difficulties, necrotizing enterocolitis, intracranial hemorrhage, and mortality (3-9).

Echocardiography and physical examination for hemodynamically significant PDA in preterm infants are inadequate in deciding medical treatment or surgical ligation during the first days of life. The benefit of prophylactic intervention (within the first $24 \mathrm{~h}$ after birth) has been found to be controversial in randomized trials, but early indomethacin treatment is believed to reduce the morbidity risk (10-12).

B-type natriuretic peptide (BNP) is synthesized by human cardiac myocytes as a 108-amino acid prohormone (proBNP), which is cleaved to the 32-residue BNP and the 76-residue $\mathrm{N}$-terminal fragment of proBNP (NT-proBNP). BNP regulates extracellular fluid volume and blood pressure by natriuresis, diuresis, vasodilatation, and antagonism of the reninangiotensin-aldosterone system. Both, BNP and NT-proBNP,

Received January 2, 2008; accepted April 2, 2008.

Correspondence: Christoph Czernik, M.D., Department of Neonatology, Charité Virchow Hospital, Medical University Berlin, Augustenburger Platz 1, 13353 Berlin, Germany; e-mail: christoph.czernik@charite.de have been used to assess cardiac dysfunction in adults $(13,14)$. Previous studies have shown that plasma BNP is elevated in the presence of PDA in preterm infants $(15,16,17)$ and the hormone has been proposed as a screening tool for the diagnosis and monitoring of PDA in infants $>2 \mathrm{~d}$ of age (18-20).

However, the most urgent questions are still difficult to answer: How fast and aggressive should we be in the treatment of PDA? And what role do the plasma levels of BNP play with regard to the optimal timing of treatment?

The aim of the present study was to evaluate BNP in preterm infants $<28 \mathrm{wk}$ on the second day of life (DOL), when it is still unknown whether a PDA is significant. We hypothesized that high plasma BNP concentrations on $\mathrm{d} 2$ are associated with the need for subsequent PDA intervention. We also intended to compare BNP concentration with echocardiographic parameters such as ductal diameter and atrial/aortic root (LA/Ao) ratio. Finally, we tested the practicability of the BNP immunoassay with very small blood samples.

\section{PATIENTS AND METHODS}

A monocentric blinded prospective clinical study was conducted at our Perinatal Center from August 1, 2005 to April 30, 2007. The study protocol was approved by the Ethics Committee of the Medical Faculty (Reg. No. EA2/198/ 05), and written informed parental consent was obtained. According to our preliminary power analysis, a sufficient statistical significance level of $p<0.05$ and statistical power of $90 \%$ (21) were achieved with 40 infants in the control group and 20 infants in the intervention group to test the hypothesis. The study design is shown in Figure 1 and the clinical data of the patients are given in Table 1. The following definitions were used: Necrotizing enterocolitis was diagnosed on the basis of clinical signs confirmed by the radiographic presence of pneumatosis intestinalis, portal air, or pneumoperitoneum. Retinopathy of prematurity was staged according to international classifications and was diagnosed by a pediatric ophthalmologist. Bronchopulmonary dysplasia was defined by the need for supplemental oxygen and by abnormal chest x-ray finding at $28 \mathrm{~d}$ of life. Intraventricular hemorrhage was classified according to Papile et al. (22). Neonatal sepsis was defined as any systemic infection documented by positive blood culture.

Measurement of plasma B-type natriuretic peptide. Blood samples (100 $\mu \mathrm{L})$ were collected in K-EDTA microtubes within $24-48 \mathrm{~h}$ of age through umbilical artery catheter aspiration or venous puncture. The samples were spun at $7000 \mathrm{rpm}$ (eppendorf microtube centrifuge) for $3 \mathrm{~min}$. Platelet-free plasma was stored at $-20^{\circ} \mathrm{C}$ until BNP analysis. The BNP assay was performed with an automated chemiluminescence immunoassay on the ADVIA Centaur analyzer (Siemens/Bayer Diagnostic Division, Fernwald, Germany). This analyzer requires $0.2 \mathrm{~mL}$ as a minimal sample volume for a BNP assay using optimized sample tubes: We therefore used 1:10 dilution of the original EDTA-plasma in the company's assigned diluent. Company data show a mean $97 \%$ recovery of BNP in diluted samples. Accordingly, the original measuring range $(2-5000 \mathrm{pg} / \mathrm{mL})$

Abbreviations: Ao, aortic root; BNP, B-type natriuretic peptide; LA, left atrium; PDA, patent ductus arteriosus 


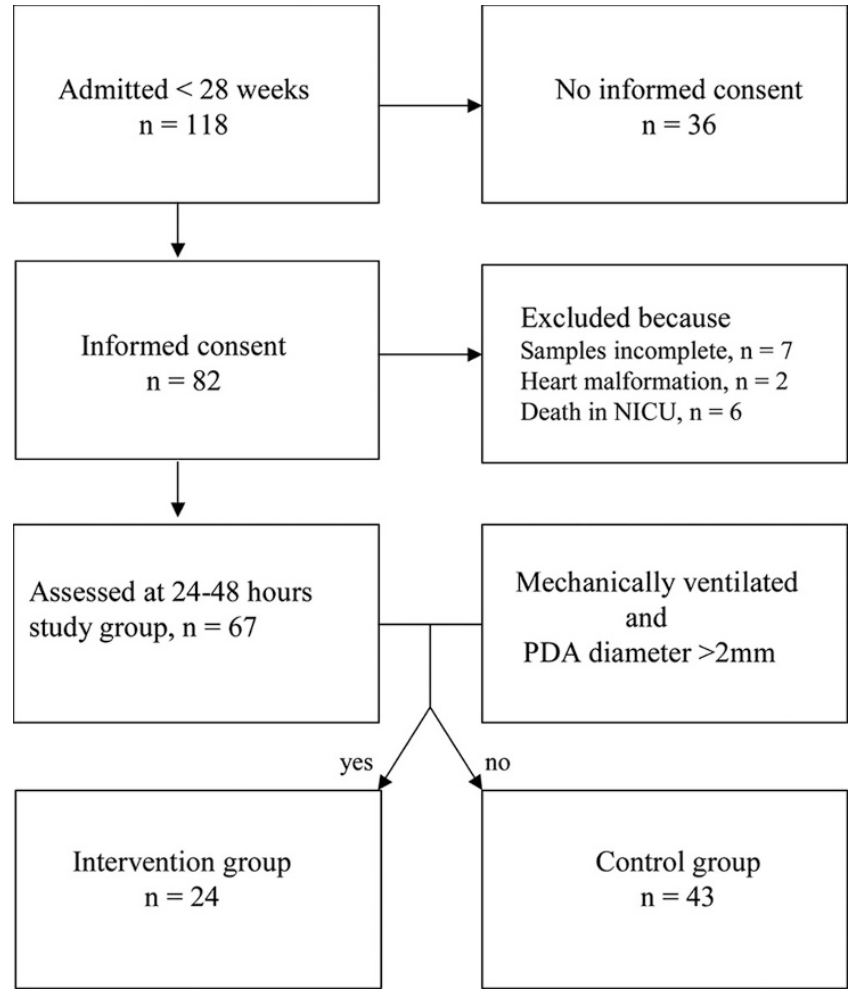

Figure 1. Selection and exclusion of study patients. BNP, B-type natriuretic peptide; NICU, neonatal intensive care unit.

Table 1. Clinical characteristics of infants with and without PDA intervention

\begin{tabular}{|c|c|c|c|}
\hline & $\begin{array}{c}\text { Intervention } \\
\mathrm{n}=24\end{array}$ & $\begin{array}{l}\text { Control } \\
\mathrm{n}=43\end{array}$ & $p$ \\
\hline \multicolumn{4}{|l|}{ Baseline characteristics } \\
\hline Maternal infection, n (\%) & $6(25)$ & $15(35)$ & 0.40 \\
\hline $\begin{array}{l}\text { Antenatal steroids } \\
\text { (complete) }\end{array}$ & $9(38)$ & $34(79)$ & 0.002 \\
\hline Gestational age (wk) & $25(24-26)$ & $26(25-27)$ & $<0.001$ \\
\hline Birth weight (g) & $737(650-827)$ & $948(720-1100)$ & 0.002 \\
\hline Arterial cord blood $\mathrm{pH}$ & $7.30(7.28-7.36)$ & $7.28(7.26-7.32)$ & 0.07 \\
\hline Apgar at $1 \mathrm{~min}$ & $4(3-5)$ & $5(4-6)$ & 0.04 \\
\hline Apgar at $5 \mathrm{~min}$ & $7(6-7)$ & $8(7-8)$ & 0.003 \\
\hline CRIB score & $7(5-9)$ & $4(1.5-7)$ & 0.001 \\
\hline Male gender, n (\%) & $9(38)$ & $21(49)$ & 0.447 \\
\hline \multicolumn{4}{|l|}{ Postnatal course } \\
\hline $\begin{array}{l}\text { Positive pressure } \\
\text { ventilation (days) }\end{array}$ & $20(10-25)$ & $0.5(0-2.75)$ & $<0.001$ \\
\hline $\begin{array}{l}\text { Supplemental oxygen } \\
\text { (days) }\end{array}$ & $59(7-86)$ & $2(0-39.5)$ & 0.001 \\
\hline Hospitalization (days) & $89(67-103)$ & $68(58-81)$ & 0.008 \\
\hline IVH $\mathrm{I}^{\circ}-\mathrm{II}^{\circ}, \mathrm{n}(\%)$ & $6(25)$ & $1(2)$ & 0.004 \\
\hline IVH III ${ }^{\circ}-\mathrm{IV}^{\circ}, \mathrm{n}(\%)$ & $1(4)$ & 0 & - \\
\hline $\begin{array}{r}\text { Bronchopulmonary } \\
\text { dysplasia, n (\%) }\end{array}$ & $8(33)$ & $4(9)$ & 0.015 \\
\hline Sepsis, n (\%) & $6(25)$ & $11(25)$ & 0.99 \\
\hline $\begin{array}{l}\text { Retinopathy of } \\
\text { prematurity, } \mathrm{n}(\%)\end{array}$ & $9(38)$ & $2(5)$ & 0.003 \\
\hline $\begin{array}{l}\text { Necrotizing } \\
\quad \text { enterocolitis, n (\%) }\end{array}$ & $3(12)$ & $1(2)$ & 0.127 \\
\hline
\end{tabular}

Data are given as patient number (\%) or median (interquartile range).

moved to values between 20 and $50,000 \mathrm{pg} / \mathrm{mL}$ (data from the manufacturer). In the infants treated for PDA we collected additional blood samples $2-4 \mathrm{~h}$ before and $24 \mathrm{~h}$ after the intervention.
Echocardiography. Color Doppler echocardiography (ATL HDI 35007.5 $\mathrm{MHz}$ transducer) was performed at the age of $24-48 \mathrm{~h}$ by a pediatric cardiologist who was blinded to the results of the BNP measurements. The ratio of the left atrial diameter to aortic diameter was measured in the parasternal long-axis (norm value 1-1.3). PDA diameter was determined in the parasternal short-axis.

Neonates without indication for ductus intervention at $24-48 \mathrm{~h}$, who were later clinically suspected of having a significant PDA, e.g. need for ventilatory support, received daily echocardiographic evaluation.

Criteria for ductus intervention. The indication for ductus intervention was based on the presence of the following three previously established criteria (23-25):

1. Need for ventilatory support.

2. Narrowest ductal diameter $>2 \mathrm{~mm}$.

3. PDA with left-to-right shunt.

Management of PDA. Infants fulfilling our criteria for ductus intervention received indomethacin if not contraindicated. The initial dose regime was 0.2 $\mathrm{mg} / \mathrm{kg}$ i.v. followed by two additional doses of $0.2 \mathrm{mg} / \mathrm{kg}$ at intervals of $12 \mathrm{~h}$ and three additional doses of $0.1 \mathrm{mg} / \mathrm{kg}$ at intervals of $24 \mathrm{~h}$. Subsequently, clinical and echocardiographic assessment of PDA was performed after the initial course of indomethacin. Whether our criteria for ductus intervention were fulfilled again, a second course of indomethacin was administered. Surgical closure was performed when indomethacin was contraindicated or the PDA remained despite two courses of indomethacin.

Statistical analysis. Data were analyzed with SPSS for Windows (V.12; SPSS, Chicago, IL). Values are presented as median and interquartile range. Group comparisons were performed with the Mann-Whitney U test and the $\chi^{2}$ test. The positive predictive value, negative predictive value, sensitivity, specificity, and likelihood ratio of BNP level for ductus intervention were assessed by receiver operating characteristic curve test to determine optimal cutoff values. Correlation of BNP and echocardiographic parameters were compared with the Spearman correlation $(R)$. Forward, stepwise logistic regression analyses were performed to assess whether variables were independent predictors for ductus intervention. $p<0.05$ was considered to be statistically significant.

\section{RESULTS}

Infants in the intervention group received lower amounts of antenatal steroids, were less mature, were smaller, had higher clinical risk index for babies and lower Apgar scores than control infants (Table 1). They received longer ventilation, supplemental oxygen, and hospitalization and suffered more frequently from intraventricular hemorrhage, bronchopulmonary dysplasia, and retinopathy of prematurity.

BNP concentration. In the intervention group, plasma BNP concentrations ranged from 53 to $5570 \mathrm{pg} / \mathrm{mL}$ (median 1069 $(564-1845) \mathrm{pg} / \mathrm{mL}$ ) on d 2. BNP concentrations in the control group were lower $(p<0.001)$, ranging from 23 to 1669 $\mathrm{pg} / \mathrm{mL}$ (median 247 (121-463) pg/mL).

The first PDA intervention started between 35 and $280 \mathrm{~h}$ of life (median $85.5(50.3-145.5)$ h). Only 8 of 24 infants fulfilled our criteria for ductus intervention at time of primary evaluation (35-52 h). Individual BNP courses are presented firstly for ductus intervention with indomethacin (16 patients) and secondly for indomethacin + surgical ligation (eight patients) (Figs. $2 A$ and $B$ ). There were no significant differences between the BNP levels in the two intervention groups. After pharmacological treatment, or surgical ligation, cardiac recompensation was reflected by decreasing BNP levels, as demonstrated in Figure 2 (median 87 (17-130) pg/mL).

Echocardiography. Preterm infants with ductus intervention had significantly greater ductal diameter (median 2.5 $(2.2-2.7) \mathrm{mm}$ versus $1.6(1.3-2.0, p<0.001))$ and higher LA/Ao-ratio (median $1.6(1.4-1.8)$ versus $1.2(1.0-1.3, p<$ $0.001)$ ) than the control group. 

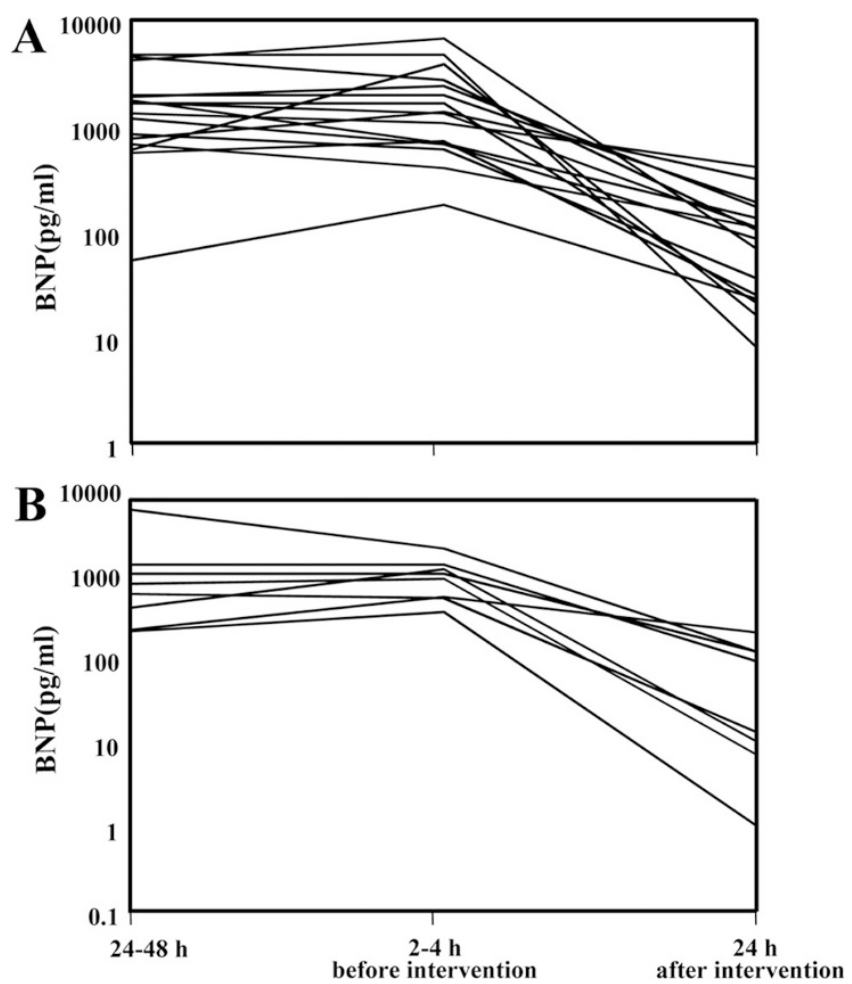

Figure 2. Individual B-type natriuretic peptide concentrations in (A) 16 infants with indomethacin treatment and in $(B)$ eight infants with indomethacin and surgical ligation according to the time of sampling: At the age of 24-48 h (first marking); $2-4 \mathrm{~h}$ before first intervention (second marking); $24 \mathrm{~h}$ after last intervention (third marking).

The correlation between BNP plasma concentrations and the LA/Ao-ratio was $R=0.54(p<0.001)$, between BNP plasma values and ductal diameter $R=0.46$, $(p<0.001)$, and between ductal diameter and LA/Ao-ratio $R=0.49,(p=$ 0.01 ) at the age of 24 to $48 \mathrm{~h}$ of life.

Cutoff values and prognosis. The area under the receiver operating characteristic curve for prediction of ductus intervention was $0.86, p<0.001$ (Fig. 3). Some cutoff values are proposed in Table 2 and compared with the LA/Ao-ratio $>1.3$ and ductal diameter $>1.5 \mathrm{~mm}$. The optimal cutoff of BNP concentration for the prediction of ductus intervention was found to be $>550 \mathrm{pg} / \mathrm{mL}$. In combination with ductal diameter $>1.5 \mathrm{~mm} \mathrm{BNP}$ has the best predictive value.

Finally, the logistic stepwise regression analysis, taking into consideration gestational age, birthweight, BNP level, and LA/Ao-ratio, showed that BNP and LA/Ao-ratio were independent variables for the prediction of ductus intervention with a positive predictive value of $91 \%$.

\section{DISCUSSION}

Our data confirm the hypothesis that high plasma BNP concentrations on $\mathrm{d} 2$ are associated with the need for subsequent PDA intervention. We investigated preterm infants $<28$ wk because they frequently fail to undergo spontaneous ductus closure (25).

The present study demonstrates that in preterm infants $<28$ wk on the second DOL, when clinical signs are absent and echocardiographic markers for the timing of ductus interven-

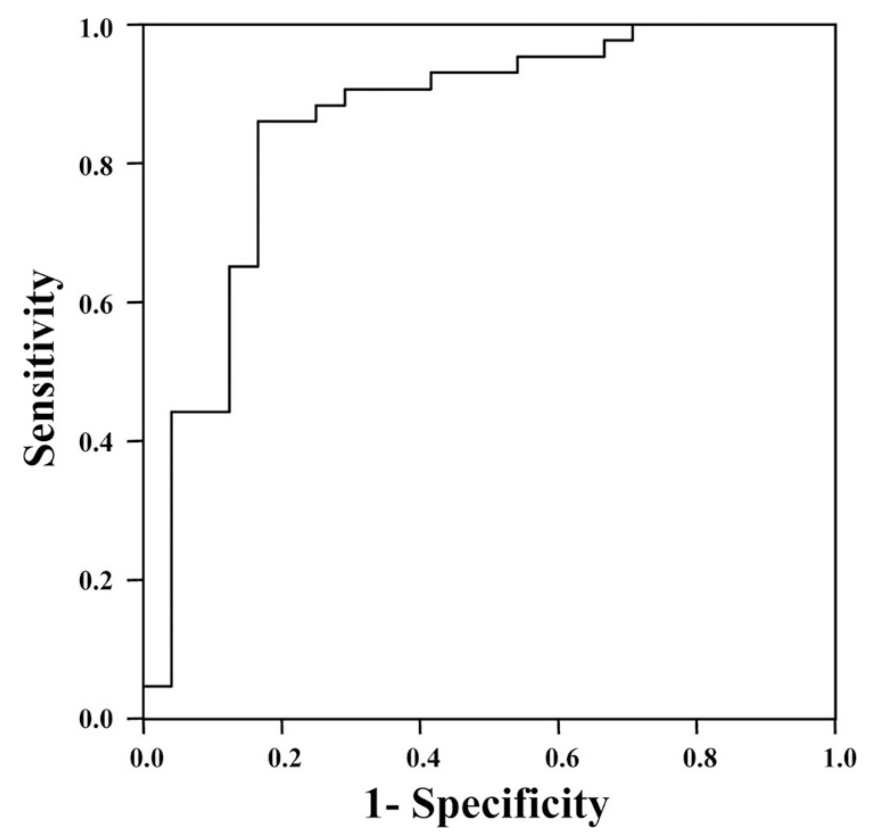

Figure 3. Receiver operating characteristic curve describing the ability of B-type natriuretic peptide to predict a ductus intervention at the age of $24-48 \mathrm{~h}$ in preterm infants $<28 \mathrm{wk}$. Area under the curve: 0.86 (95\% confidence interval: 0.752-0.959; $p<0.001)$.

Table 2. Cutoff values for prediction of ductus intervention

\begin{tabular}{lcccc}
\hline BNP $(\mathrm{pg} / \mathrm{mL})$ & $\begin{array}{c}\text { Sensitivity } \\
(\%)\end{array}$ & $\begin{array}{c}\text { Specificity } \\
(\%)\end{array}$ & $\begin{array}{c}\text { PPV } \\
(\%)\end{array}$ & $\begin{array}{c}\text { NPV } \\
(\%)\end{array}$ \\
\hline$>380$ & 88 & 65 & 58 & 90 \\
$>450$ & 83 & 74 & 65 & 89 \\
$>500$ & 83 & 84 & 74 & 90 \\
$>550$ & 83 & 86 & 77 & 90 \\
$>600$ & 71 & 88 & 77 & 84 \\
$>650$ & 71 & 91 & 81 & 85 \\
LA/Ao >1.3 & 82 & 85 & 75 & 89 \\
LA/Ao >1.3 & 62 & 95 & 87 & 84 \\
$\quad$ and BNP & & & & \\
$\quad>550$ & & & & \\
Ductal diameter & 96 & 32 & 55 & 90 \\
$\quad>1.5$ mm & & & & \\
Ductal diameter & 83 & 93 & 91 & 86 \\
$\quad>1.5$ mm and & & & & \\
$\quad$ BNP >550 & & & & \\
\hline
\end{tabular}

PPV indicates positive predictive value; NPV, negative predictive value; BNP, B-type natriuretic peptide.

tion are controversial, plasma BNP levels are strongly related to the need for subsequent ductus intervention and not only to the presence of PDA. The BNP levels in the study group, which underwent ductus intervention, were significantly higher than in the control group. In contrast to previous studies, which found BNP to be elevated in symptomatic PDA at an age of $>2 \mathrm{~d}(18,19,20)$, our study established elevated BNP as a prognostic marker already at the age of $24-48 \mathrm{~h}$. Only eight of 24 patients in the intervention group had indication for ductus intervention due to our criteria on the second DOL (between 35 and $52 \mathrm{~h}$ ) whereas 16 patients needed a subsequent ductus intervention (between 62 and $280 \mathrm{~h}$ ). In retrospective, knowledge of BNP levels in these infants might have added clinically useful information for the timing of ductus intervention. Because our echocardiographic interven- 
tion criteria were not fulfilled in one-third of the infants at time of the first screening, BNP levels would have been helpful in the selection of these infants to be treated at an early presymptomatic stage of PDA. Our criteria for medical treatment or surgical intervention were stricter than in other studies with ductal diameter greater than $2 \mathrm{~mm}$ and the need for mechanical ventilation (23-25). However, at this early stage, the main risk is to expose infants unnecessarily to treatment in whom the ductus may close spontaneously. All infants in the control group had lower BNP levels and did not need a ductus intervention.

We defined a cutoff BNP value of $>550 \mathrm{pg} / \mathrm{mL}$ as having high sensitivity and specificity for ductus intervention. The high cutoff level can be explained by the early age compared with the lower cutoff level $>300 \mathrm{pg} / \mathrm{mL}$ for infants $>2 \mathrm{~d}$ of life, for example in the study by Flynn et al. (19). Of course, circulating plasma BNP is influenced by several factors such as infection, medical management and hemodynamic effects (26), but all infants had the same clinical standard and infants with heart disease had been excluded. Furthermore, we confirmed that the successful closure of the ductus is reflected by a corresponding decrease in plasma BNP concentrations and can also be helpful in monitoring the efficiency of pharmacological treatment of PDA.

The plasma half-life of the biologically inactive NTproBNP is longer $(120 \mathrm{~min})$ than that of the active hormone BNP (20 min), which is reflected by the higher serum concentrations of NT-proBNP with a wide range during the first days of life $(27,28,29)$. BNP is excreted after cleavage by membrane-bound neutral peptidase and is not that dependent on renal function, especially in first days of life (13). Thus, we decided to investigate BNP and not NT-proBNP.

Overall, in this study, circulating BNP levels correlated well to the echocardiographic and clinical assessment of PDA. The LA/Ao-ratio, the ductal diameter, ventilation days, and the supplemental oxygen days were significantly higher in the intervention group.

Our results are in accordance with those of previous studies, where shunt-induced LA/Ao-ratio $\geq 1.4$ and ductal diameter $\geq 1.5 \mathrm{~mm}$ indicate a hemodynamically significant PDA (23$25,30)$. Evans and Iyer showed that in infants $<1500 \mathrm{~g}$, if the ductal diameter was $>1.5 \mathrm{~mm}$, the shunt was usually significant and if it was $>2 \mathrm{~mm}$, the shunt was always significant (pulmonary/systemic flow ratio $>2: 1$ ). Furthermore, we found that BNP combined with ductal diameter $>1.5 \mathrm{~mm}$ provides better specificity and positive predictive value for ductus intervention than BNP or ductal diameter alone.

Because the optimal timing to treat the PDA in premature infants is an unresolved issue and controversy still exists about the indication for ductus intervention, we believe that BNP measurement can be used as an adjunct to echocardiography and may be helpful for the timing of ductus intervention. However, deciding whether a PDA is pathologic or harmful is still difficult and the criteria are not clear in the absence of randomized trials with long-term outcome.

There are a number of limitations to this study. The decision to treat a PDA, and therefore inclusion in the intervention group used a nonrandomized approach. It was based on clinical and echocardiographic criteria, and some variability in practice may have occurred. Reopening of the ductus, e.g. in infection, has not been addressed by our study.

In conclusion, although increasing circulating BNP level can be a useful biologic marker in neonatal intensive care units to predict the need for early PDA treatment, it cannot replace echocardiography in diagnosing a PDA. Plasma BNP values of above $550 \mathrm{pg} / \mathrm{mL}$ have high sensitivity and specificity to predict the necessity of medical PDA intervention in ventilated preterm infants $<28$ wk already on d 2 of life. Future research is required to further define the diagnostic accuracy of BNP in a larger patient population.

Acknowledgments. We thank the doctors and nurses of our neonatal intensive care unit for assistance during the examinations. The BNP assays were gifts from Bayer Diagnostics, Germany. We thank Dr. Werner Hopfenmüller for reviewing the statistics, and Anne Gale for editorial assistance.

\section{REFERENCES}

1. Wyllie J 2003 Treatment of patent ductus arteriosus. Semin Neonatol 8:425-432

2. Evans N 1993 Diagnosis of patent ductus arteriosus in the preterm newborn. Arch Dis Child 68:58-61

3. Shimada S, Kasai T, Hoshi A, Murata A, Chida S 2003 Cardiocirculatory effects of patent ductus arteriosus in extremely low-birth-weight infants with respiratory distress syndrome. Pediatr Int 45:255-262

4. Meyers RL, Alpan G, Lin E, Clyman RI 1991 Patent ductus arteriosus, indomethacin, and intestinal distension: effects on intestinal blood flow and oxygen consumption. Pediatr Res 29:569-574

5. Bassan H, Feldman H, Limperopoulos C, Benson C, Ringer S, Veracruz E, Soul J, Volpe J, Plessis A 2006 Periventricular hemorrhagic infarction: risk factors and neonatal outcome. Pediatr Neurol 35:85-92

6. Redline RW, Wilson-Costello D, Hack M 2002 Placental and other perinatal risk factors for chronic lung disease in very low birth weight infants. Pediatr Res 52:713-719

7. Evans N, Kluckow M 1996 Early ductal shunting and intraventricular haemorrhage in ventilated preterm infants. Arch Dis Child Fetal Neonatal Ed 75:F183-F186

8. Dollberg S, Lusky A, Reichman B 2005 Patent ductus arteriosus, indomethacin and necrotizing enterocolitis in very low birth weight infants: a population-based study. J Pediatr Gastroenterol Nutr 40:184-188

9. Rojas MA, Gonzalez A, Bancalari E, Claure N, Silva-Neto G 1995 Changing trends in the epidemiology and pathogenesis of neonatal chronic lung disease. J Pediatr 126:605-610

10. Ment LR, Oh W, Ehrenkranz RA, Philip AG, Vohr B, Allan W, Duncan CC, Scott DT, Taylor KJ, Katz KH 1994 Low-dose indomethacin and prevention of intraventricular hemorrhage: a multicenter randomized trial. Pediatrics 93:543-550

11. Schmidt B, Davis P, Moddemann D, Ohlsson A, Roberts RS, Saigal S, Solimano A, Vincer M, Wright LL 2001 Long-term effects of indomethacin prophylaxis in extremely-low-birth-weight infants. N Engl J Med 344:1966-1972

12. Marshall DD, Kotelchuk M, Young TE, Bose CL, Kruyer L, O‘Shea TM 1999 Risk factors for chronic lung disease in the surfactant era: a North Carolina populationbased study of very low birth weight infants. Pediatrics 104:1345-1350

13. Vanderheyden M, Bartunek J, Goethals M 2004 Brain and other natriuretic peptides: molecular aspects. Eur J Heart Fail 6:261-268

14. Wu AH, Smith A, Wieczorek S, Mather JF, Duncan B, White CM, McGill C, Katten D, Heller G 2003 Biological variation for N-terminal Pro- and B-type natriuretic peptides and implications for therapeutic monitoring of patients with congestive heart failure. Am J Cardiol 92:628-631

15. Puddy VF, Amirmansour C, Williams AF, Singer DR 2002 Plasma brain natriuretic peptide as a predictor of haemodynamically significant patent ductus arteriosus in preterm infants. Clin Sci 103:75-77

16. Holmstrom H, Omland T 2002 Natriuretic peptides as markers of patent ductus arteriosus in preterm infants. Clin Sci 103:79-80

17. Holmstrom H, Hall C, Thaulow E 2001 Plasma levels of natriuretic peptides and hemodynamic assessment of patent ductus arteriosus in preterm infants. Acta Paediatr 90:184-191

18. Sanjeev S, Pettersen M, Lua J, Thomas R, Shankaran S, L‘Ecuyer T 2005 Role of plasma B-type natriuretic peptide in screening for hemodynamically significant patent ductus arteriosus in preterm neonates. J Perinatol 25:709-713

19. Flynn PA, da Garca RL, Auld PA, Nesin M, Kleinman CS 2005 The use of a bedside assay for plasma B-type natriuretic peptide as a biomarker in the management of patent ductus arteriosus in premature neonates. J Pediatr 147:38-42

20. Choi BM, Lee KH, Eun BL, Yoo KH, Hong YS, Son CS, Lee JW 2005 Utility of rapid B-type natriuretic peptide assay for diagnosis of symptomatic patent ductus arteriosus in preterm infants. Pediatrics 115:e255-e261 
21. Fleiss JL 1981 Statistical Methods for Rates and Proportions, 2nd Ed. Wiley \& Sons, New York, pp 38-45

22. Papile LA, Burstein J, Burstein R, Koffler H 1978 Incidence and evolution of subependymal and intraventricular hemorrhage: a study of infants with birth weights less than 1,500 gm. J Pediatr 92:529-534

23. Evans N, Iyer P 1994 Assessment of ductus arteriosus shunt in preterm infants supported by mechanical ventilation: effect of inter-atrial shunting. J Pediatr 125:778-785

24. Evans N, Iyer P 1995 Longitudinal changes in the diameter of the ductus arteriosus in ventilated preterm infants: correlation with respiratory outcomes. Arch Dis Child Fetal Neonatal Ed 72:F156-F161

25. Kluckow M, Evans N 1995 Early echocardiographic prediction of symptomatic patent ductus arteriosus in preterm infants undergoing mechanical ventilation. J Pediatr 127:774-779
26. Rudiger A, Gasser S, Fischler M, Hornemann T, von Eckardstein A, Maggiorini M 2006 Comparable increase of B-type natriuretic peptide and amino-terminal pro-B type natriuretic peptide levels in patients with severe sepsis, septic shock, and acute heart failure. Crit Care Med 34:2140-2144

27. Mir TS, Marohn S, Laer S, Eiselt M, Grollmus O, Weil J 2002 Plasma concentrations of $\mathrm{N}$-terminal pro-brain natriuretic peptide in control children from the neonatal to adolescent period and in children with congestive heart failure. Pediatrics 110:e76

28. Bar-Oz B, Lev-Sagie A, Arad I, Salpeter L, Nir A 2005 N-terminal pro-B-type natriuretic peptide concentrations in mothers just before delivery, in cord blood, and in newborns. Clin Chem 51:926-927

29. Koch A, Singer H 2003 Normal values of B type natriuretic peptide in infants, children and adolescents. Heart 89:875-878

30. Iyer P, Evans N 1994 Re-evaluation of the left atrial to aortic root ratio as marker of patent ductus arteriosus. Arch Dis Child Fetal Neonatal Ed 70:F112-F117 